\title{
Growth of $\mathrm{LiNaSO}_{4}$ single crystals from a solution of stoichiometric pH value
}

\author{
S R SAHAYA PRABAHARAN, P MUTHUSUBRAMANIAN, \\ R SARAVANAN* and S K MOHANLAL* \\ School of Energy Sciences, ${ }^{*}$ School of Physics, Madurai Kamaraj University, Madurai \\ 625021 , India
}

MS received 24 December 1990; revised 19 July 1991

\begin{abstract}
Single crystals of $\mathrm{LiNaSO}_{4}$ were grown without adjusting the pH value of equimolar aqueous solution containing $\mathrm{Li}_{2} \mathrm{SO}_{4} \cdot \mathrm{H}_{2} \mathrm{O}$ and $\mathrm{NaHSO}_{4}$ at $30^{\circ} \mathrm{C}$. As-grown crystals were characterized using X-ray, IR, Raman and other crystal perfection studies such as chemical etching, scanning electron micrograph and microhardness measurements. Atomic absorption technique was adopted to verify the composition of $\mathrm{Li}^{+}$and $\mathrm{Na}^{+}$ion content and these were found to be consistent with the desired composition to within $\pm 6 \mathrm{~mol} \%$.
\end{abstract}

Keywords. $\mathrm{LiNaSO}_{4}$ crystals; chemical etching; microhardness.

\section{Introduction}

In the search for good solid electrolyte materials for applications in solid state batteries, fuel cells, etc. (Goodenough 1984), sulphate-based alkali cation systems are vital for achieving a good ionic conductivity during the solid-solid phase transitions with large latent heat of transition (Heed et al 1977). Many systems with another lithium salt or sulphate have been investigated to obtain a stable solid solution with the $\mathrm{Li}_{2} \mathrm{SO}_{4}$ cubic structure or double sulphates which might be good ionic conductors. Until recently, several attempts were made to stabilize the cubic high conducting phase of $\mathrm{Li}_{2} \mathrm{SO}_{4}$ with other alkali sulphates such as sodium and potassium (Josefson and Kvist 1969; Schroeder et al 1972; Schroeder and Sjŏblem 1980; Singh et al 1980; Nilsson 1981; Teeter and Frech 1982). Extensive microscopic investigations on these crystals require good perfection in the crystal. Here, we report a new procedure to grow single crystals of $\mathrm{LiNaSO}_{4}$ and the study of its physical characterization using X-ray, IR, Raman and other crystal perfection studies viz. etching, scanning electron microscopy (SEM) and microhardness.

\section{Experimental}

The $\mathrm{LiNaSO}_{4}$ binary cation single crystal used in the present investigation was grown by slow evaporation from an aqueous solution containing equimolar amounts of $\mathrm{Li}_{2} \mathrm{SO}_{4} \cdot \mathrm{H}_{2} \mathrm{O}$ and $\mathrm{NaHSO}_{4}$ without adjusting the $\mathrm{pH}$ value to 2 . In the conventional procedure Teeter and Frech (1982) used equimolar binary combination of $\mathrm{Li}_{2} \mathrm{SO}_{4} \cdot \mathrm{H}_{2} \mathrm{O}$ and $\mathrm{Na}_{2} \mathrm{SO}_{4}$ as starting materials and the growth was accomplished by maintaining the solution temperature at $70^{\circ} \mathrm{C}$ with $\mathrm{pH} 2$. In the present study, $\mathrm{NaHSO}_{4}$ was used as one of the parent materials instead of $\mathrm{Na}_{2} \mathrm{SO}_{4}$ without adjusting the solution $\mathrm{pH}$ value and the growth temperature was maintained at $30^{\circ} \mathrm{C}$. The crystals thus obtained had maximum dimensions of $4 \times 8 \times 2 \mathrm{~mm}$ having good optical 


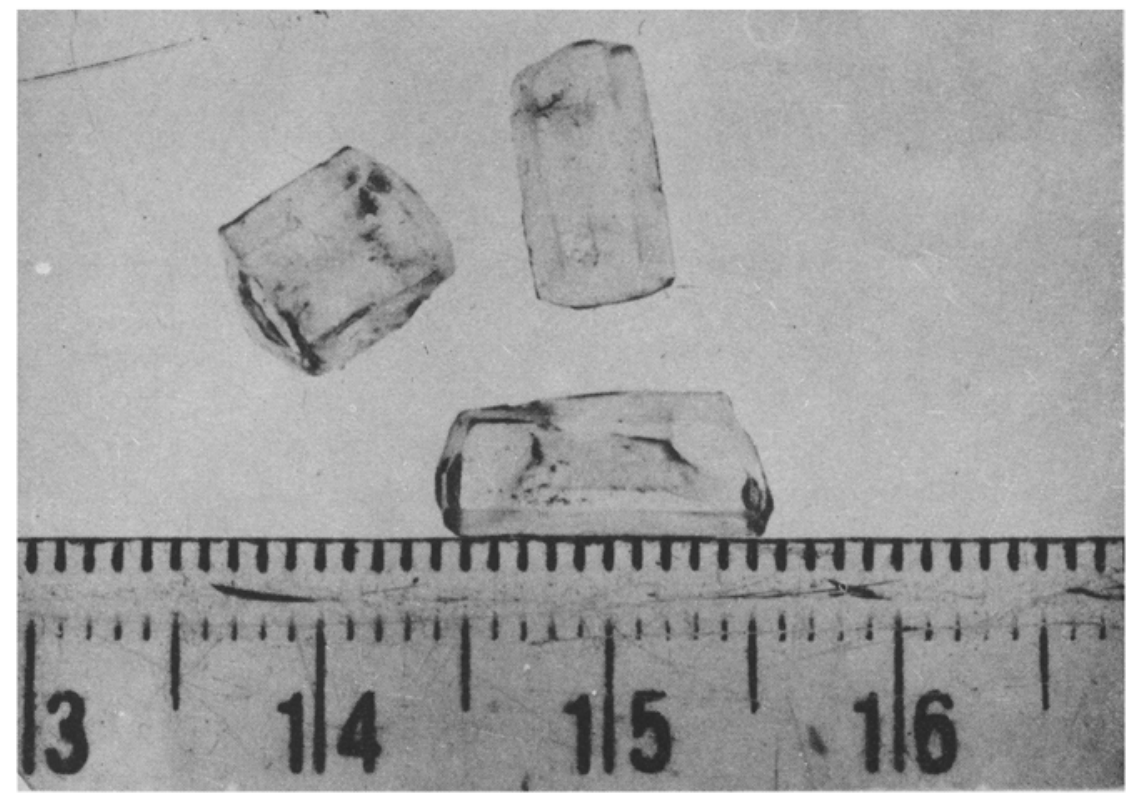

Figure 1. Photograph of actual crystals grown.

transparency with platelet habits (figure 1). Nucleation started within $24 \mathrm{~h}$ and the crystals were formed within 3 days. The $\mathrm{Li}^{+}$and $\mathrm{Na}^{+}$ion contents were analysed by atomic absorption technique using GBC 902 double beam atomic absorption spectrometer. It was found that the analysed composition was consistent with the desired compositions to within $\pm 6 \mathrm{~mol} \%$.

\section{Results and discussion}

The as-grown crystals were analysed using $X$-ray, IR and Raman physical techniques and their density was measured using floatation technique having a mixture of bromoform and carbon tetrachloride and was found to be $2.523 \mathrm{~g} / \mathrm{cc}$. The cell dimensions of the crystals were determined by the oscillation and Weissenberg technique (Burger 1958) with nickel-filtered $\mathrm{CuK}_{\alpha}$ radiation. The preliminary crystallographic data are presented in table 1.

IR spectrum of the grown crystals was recorded on a Perkin Elmer 588 spectrophotometer using the $\mathrm{KBr}$ pellet technique and the Raman spectrum in a SPEX 1401 spectrophotometer using the $5145 \AA$ green line of $\mathrm{Ar}^{+}$laser as the excitation source (figures 2 and 3 ) for powder sample. The spectra were expected to have bands due to vibrations of $\mathrm{SO}_{4}$ group frequencies. A free $\mathrm{SO}_{4}^{2-}$ ion ( $T_{d}$ symmetry) had four normal modes of vibrations, which appeared at 981, 451, 1104 and $613 \mathrm{~cm}^{-1}$ (Herzberg 1960) for $v_{1}, v_{2}, v_{3}$ and $v_{4}$ respectively. The bands due to external vibrations of this group and $\mathrm{Na}-\mathrm{O}$ translational group frequencies were not observed as the lower limit of the instrument was only up to $200 \mathrm{~cm}^{-1}$ in the IR spectrum. Nevertheless, $\mathrm{Li}-\mathrm{O}$ translational frequencies were observed between 300 and $450 \mathrm{~cm}^{-1}$.

In IR, a strong broad band covering the region $1050-1200 \mathrm{~cm}^{-1}$ was attributed to the asymmetric stretching mode $\left(v_{3}\right)$ of sulphate ion, whereas in Raman, three bands 
Table 1. Preliminary crystallographic data.

\begin{tabular}{|c|c|}
\hline Cell dimensions & $\begin{array}{l}a=7.657 \AA \\
c=9.878 \AA \\
\beta=119.8^{\circ}\end{array}$ \\
\hline Volume of the unit cell & $=502.56 \AA^{3}$ \\
\hline Observed density & $=2.523 \mathrm{~g} / \mathrm{cc}$ \\
\hline Calculated density & $=2.497 \mathrm{~g} / \mathrm{cc}$ \\
\hline No. of molecules in the unit cell & $=6$ \\
\hline System & $=$ Trigonal \\
\hline Space group & $=P 31 c$ \\
\hline
\end{tabular}

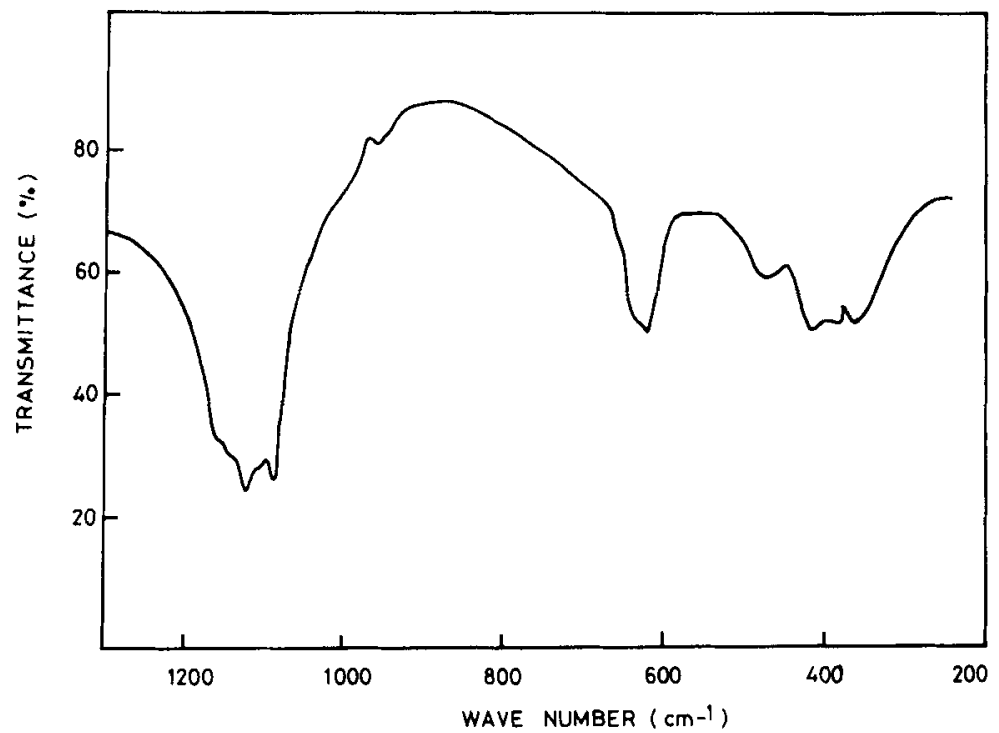

Figure 2. IR spectrum of internal optic mode region of $\mathrm{SO}_{4}^{2-}$ ion in $\mathrm{LiNaSO}_{4}$.

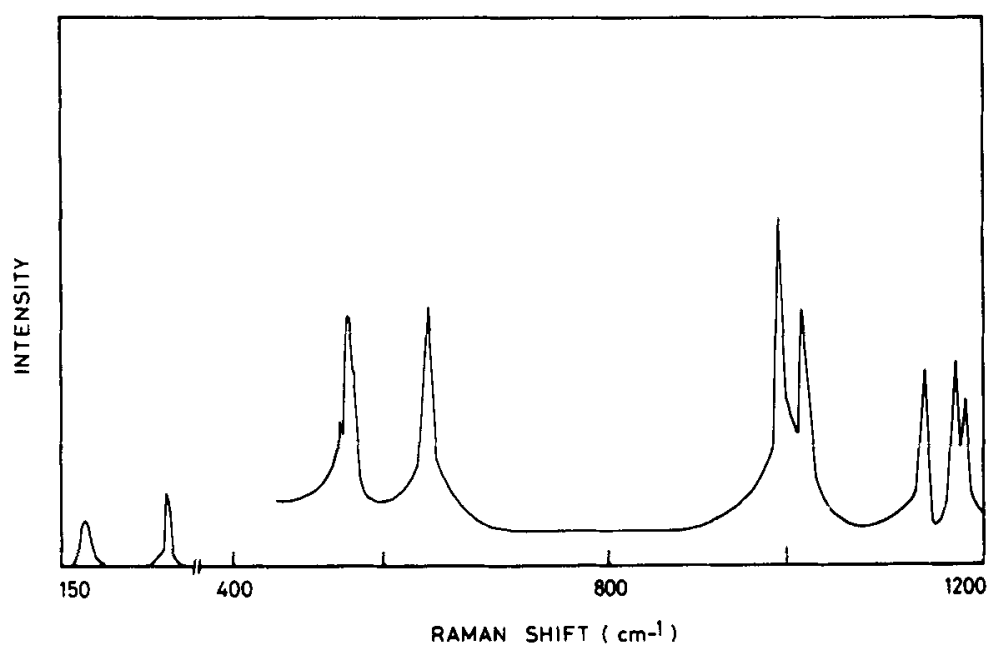

Figure 3. Laser Raman spectrum of $\mathrm{LiNaSO}_{4}$ in the region $150 \mathrm{~cm}^{-1}-1200 \mathrm{~cm}^{-1}$. 
appeared at 1184,1172 and $1121 \mathrm{~cm}^{-1}$ respectively corresponding to the asymmetric stretching mode of sulphate ion. The degeneracy of these modes was lifted completely and this may be due to crystal field effects. In Raman, the band due to the $v_{1}\left(A_{1}\right)$ mode was expected to be the most intense one. We have observed two bands at $1026 \mathrm{~cm}^{-1}$ and a strong one at $980 \mathrm{~cm}^{-1}$ for this mode. IR shows the counterpart at $1005 \mathrm{~cm}^{-1}$ and $955^{-1}$ for $v_{1}$ mode of sulphate ion. In the crystal, as the sulphate ion occupies a lower symmetry $\left(C_{1}\right)$ than its free ion symmetry $\left(T_{d}\right)$, one can expect the appearance of IR-inactive modes $v_{1}\left(A_{1}\right)$ and $v_{2}(E)$ and partial or complete lifting of the degeneracies of the degenerate modes.

In Raman, the bands due to $v_{2}(E)\left(469 \mathrm{~cm}^{-1}\right.$ and a weak shoulder at $\left.459 \mathrm{~cm}^{-1}\right)$ and $v_{4}\left(F_{2}\right)$ (a strong band at $617 \mathrm{~cm}^{-1}$ ) were lifted partly. A weak band at $475 \mathrm{~cm}^{-1}\left(v_{2}\right)$ and two medium intensity bands at 620 and $630 \mathrm{~cm}^{-1}\left(v_{4}\right)$ appeared in IR for these modes. The lithium oxygen stretching vibrations (IR: 380 and $360 \mathrm{~cm}^{-1}$; Raman: $402 \mathrm{~cm}^{-1}$ ) have also been observed. The appearance of the IR inactive $v_{1}$ and $v_{2}$ modes suggests the possibility of linear and angular distortions of $\mathrm{SO}_{4}$ tetrahedra. The shifting of the stretching modes $v_{1}$ and $v_{3}$ to high wave numbers from the free-ion value, the partial lifting of the degenerate bending mode $\left(v_{4}\right)$ and the complete splitting of the stretching mode $\left(v_{3}\right)$ indicate that the linear distortion was greater than the angular distortion. Distortions of the same type were observed for $\mathrm{LiNaSO}_{4}$ crystals using the conventional procedure (Teeter and Frech 1982). From table 3, it is seen that there are very small frequency shifts in both IR and Raman spectra when compared to conventional spectrum (Teeter and Frech 1982) and they are well within the experimental error except for a peak at $1184 \mathrm{~cm}^{-1}$ for $v_{3}$ mode of $\mathrm{SO}_{4}^{2-}$ ion and this may be due to resonance interaction between vibrating sulphate ions. This is confirmed by the presence of two lines for the non-degenerate $v_{1}$ mode.

The etch pattern obtained on the complementary faces of single crystals of $\mathrm{LiNaSO}_{4}$ is shown in figure 4. The edges of all the pits point towards the same direction confirming the formation of genuine pits. There was one-to-one correspondence of the etch pits on the two match halves and this implied that at the site of every pit there was a dislocation, but corresponding to every dislocation a pit may not necessarily be associated. The chemical etchants used were $\mathrm{H}_{2} \mathrm{SO}_{4}$ and $\mathrm{CH}_{3} \mathrm{COOH}$. The etched crystals were examined under an optical microscope. The number of pits formed was determined taking an average of the measurements on a number of etch pits. The etching time was carefully adjusted and the etch pattern obtained in this manner is shown in figure 4. As the etching time was increased, the size of the etch pits also increased and the etch pits overlapped. The etching time was therefore kept short to ensure good resolution of most of the dislocations. From the distribution of the etch

Table 2. Microhardness measurements.

\begin{tabular}{|c|c|c|}
\hline $\begin{array}{l}\text { Load } \\
P(\mathrm{~kg})\end{array}$ & $\begin{array}{c}\text { Mean diagonal of the } \\
\text { indentation mark } \\
d(\mathrm{~mm})\end{array}$ & $\begin{array}{c}\mathrm{VHN} \\
\left(\mathrm{kg} / \mathrm{mm}^{2}\right)\end{array}$ \\
\hline 0.010 & 0.0453 & $9 \cdot 03$ \\
\hline 0.025 & 0.0667 & $10 \cdot 40$ \\
\hline 0.050 & 0.0922 & $10 \cdot 90$ \\
\hline 0.075 & - & - \\
\hline $0 \cdot 100$ & 0.1533 & 7.89 \\
\hline
\end{tabular}




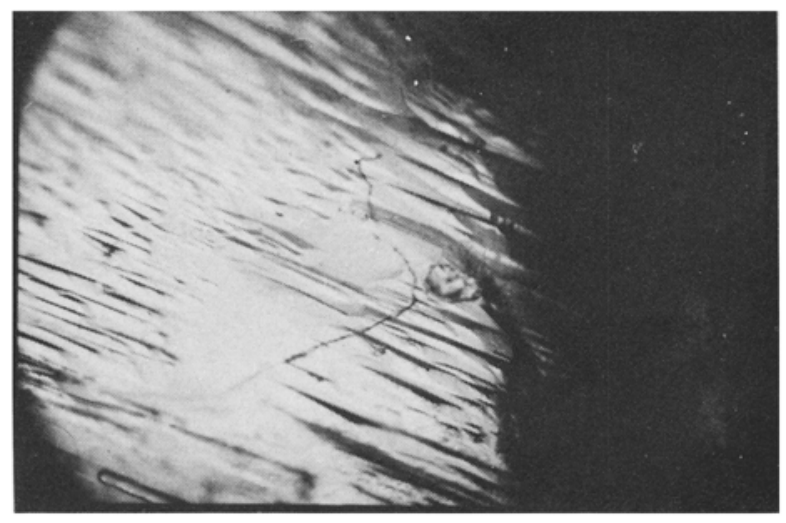

Figure 4. Rectangular-shaped etch pits on the flat face of $\mathrm{LiNaSO}_{4}$.

pits on the etched surfaces, it was observed that the dislocation density in the mixed system agreed well with literature values and several workers (Smakula et al 1962; Bhimasankaran 1974; Haribabu et al 1975) have observed the dislocation density to be greater in the mixed crystals than in the end members. They have also observed that dislocation density had a maximum value for the intermediate composition, and falls on either side towards the components. Our results for the mixed crystal agree with these observations. The estimated dislocation density value of $\mathrm{LiNaSO}_{4}$ single crystal was of the order of $1.09 \times 10^{4} / \mathrm{cm}^{2}$ (the etching time was prolonged for $20 \mathrm{~s}$ ). The etching experiments revealed the presence of a large number of dislocations around some foreign particles incorporated during the growth of the crystal. As can be seen from the photomicrograph (figure 4), the etch pit morphology was sensitive to the orientation of the crystal surface being studied, the electrochemical condition at the surface, the nature of the etchants and the optimum etching time.

The SEM picture of $\mathrm{LiNaSO}_{4}$ mixed crystal shown in figure 5 reveals the formation of microcrystals on the surfaces of the as-grown crystals. The patches in figure 5 were indicative of such microcrystals and the etching phenomenon removes the patches formed during the growth of the crystal and thus delineates the linear defects that appear in the form of etch pits.

Microhardness was studied using Vicker's pyramidal indentation for different loads, varying for 10 to $100 \mathrm{~g}$ for a constant time of indentation $(15 \mathrm{~s})$. The distance between any two indentations was such that it was 3 times greater than the diagonal length in order to avoid any mutual influence of the indentation. The length of the diagonal was measured using a micrometer eyepiece attached to the hardness tester for each microindentation made on the $(010)$ face of the crystals with pyramid diamond indentor using a hardness tester LECDM-400. Vicker's hardness number was calculated using the relation (Mott 1966) VHN $=1.854 P / d^{2}$, where $P$ is the load applied $(\mathrm{kg})$ and $d^{2}$ the diagonal of the indentation mark $(\mathrm{mm})$. The microhardness result is given in table 2. The plot of $\log (d)$ vs $\log (P)$ for $\mathrm{LiNaSO}_{4}$ (figure 6) is a straight line below and above the observed critical load regions of $50 \mathrm{~g}$. The value of slope at the low load regions in the case of $\mathrm{LiNaSO}_{4}$ crystal was approximately equal to 2 . This proves the validity of the Meyer formula ( $\mathrm{P}=\mathrm{ad}^{n}$ with $\left.n=2\right)$ (Kumareson and Devanarayan 1989) in this region. In the case of $\mathrm{LiNaSO}_{4}$, however, the lower value of the slope $(<2)$ at the 


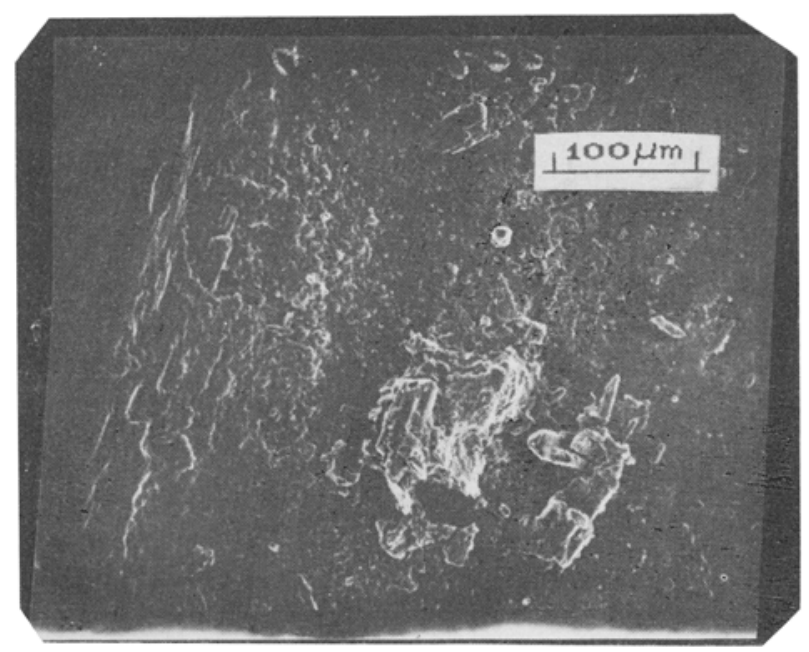

Figure 5. Scanning electron micrograph of $\mathrm{LiNaSO}_{4}$.

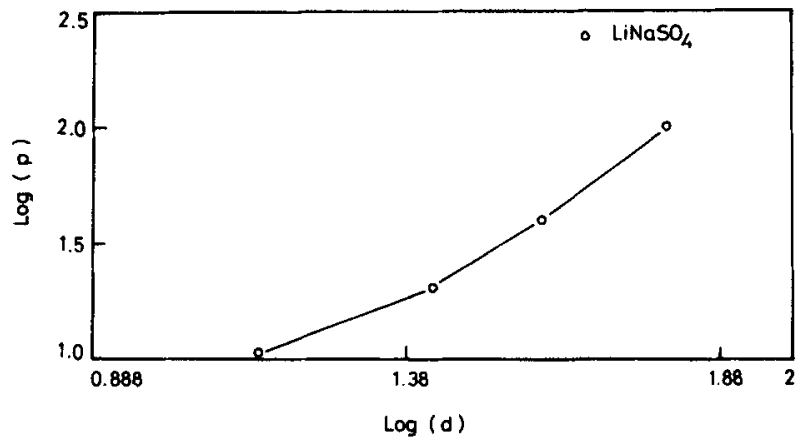

Figure 6. Variation of slope at the high and low load region of $\mathrm{LiNaSO}_{4}$.

Table 3. Frequencies $\left(\mathrm{cm}^{-1}\right)$ of $\mathrm{SO}_{4}^{2-}$ ion internal optic modes.

\begin{tabular}{lcc}
\hline & \multicolumn{2}{c}{ Raman } \\
\cline { 2 - 3 } Mode & $\mathrm{A}$ & $\mathrm{B}$ \\
\hline$v_{1}$ & 980 & 974 \\
& 1026 & 1026 \\
$v_{2}$ & 459 & - \\
& 469 & 476 \\
$v_{3}$ & 1121 & 1120 \\
& 1172 & 1173 \\
$v_{4}$ & $1184^{*}$ & - \\
& 620 & 625 \\
& 630 & 635 \\
\hline
\end{tabular}

A-Present work; B-Teeter and Frech 1982 (see text); ${ }^{*}$ due to resonance interaction between vibrating $\mathrm{SO}_{4}^{2-}$ ions. 


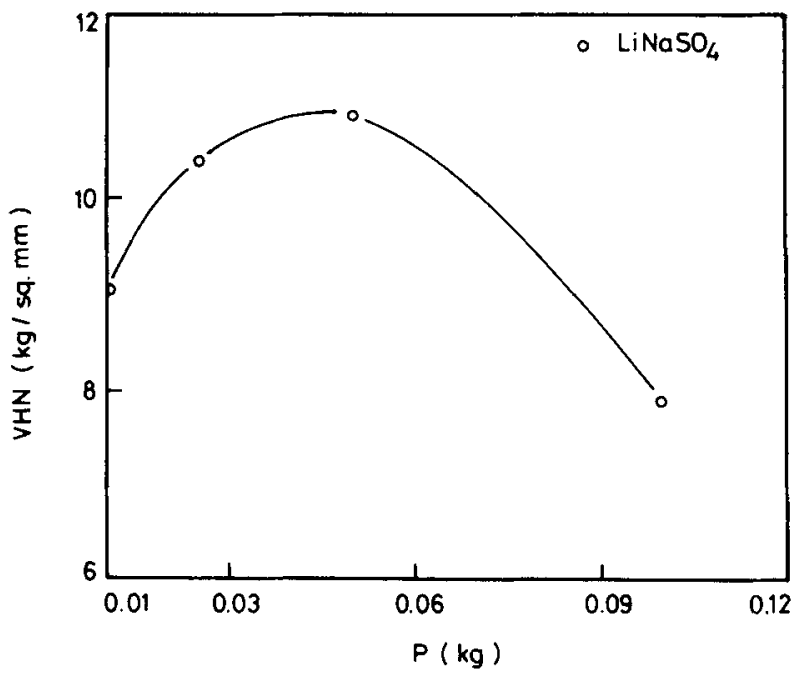

Figure 7. Variation of VHN with load of $\mathrm{LiNaSO}_{4}$.

low load region indicated that the above equation was not obeyed by the crystal when the load existed below $50 \mathrm{~g}$. However, the mean value of slope obtained for the crystal (1.93) at the high load region indicated the validity of the above equation when the load exceeded the critical value $(50 \mathrm{~g})$. The higher value of the slope for the high load regions was indicative of a higher degree of microhardness in the crystal. Figure 7 shows the variation of microhardness with load for $\mathrm{LiNaSO}_{4}$. The microhardness increased with increase of load and decreased drastically above $50 \mathrm{~g}$ of load. This indicates that the value of microhardness for $\mathrm{LiNaSO}_{4}$ was maximum at this particular load. Hence one may conclude that the binary cation sulphate crystal exhibits a maximum hardness value at an optimum load $(50 \mathrm{~g})$. Hence, we conclude that this approach reveals that one can grow good quality single crystals of $\mathrm{LiNaSO}_{4}$ with considerable dimension of $4 \times 8 \times 2 \mathrm{~mm}$ without taking any special effort during crystal growth.

\section{Acknowledgements}

One of the authors (SRSP) is grateful to Prof. T M Haridasan for encouragement. The authors (SRSP and RS) express their gratitude to Dr V Ramakrishnan for invaluable help and comments during the entire course of work. The authors also thank Mr Kanakaraj, CECRI, Karaikudi for microhardness measurements.

\section{References}

Bhimasankaran T 1974 Ph D Thesis, Osmania University, Hyderabad. India Burger M 1958 in $X$-ray crystallography (London: John Wiley) 4th edn Goodenough J 1984 Proc. R. Soc. London A393 215

Haribabu V, Subbarao U V and Venkata Ramaiah K 1975 Phys. Status Solidi A28 269

Heed B, Lunden A and Schroeder K 1977 Electrochemica. Acta 22705

Herzberg G 1960 in Infrared and Raman spectra of polyatomic molecules (New York: Von Nostrand) 2nd edn 
Josefson A M and Kvist A 1969 Z. Naturforsch. A24 466

Kumareson P and Devanarayan S 1989 J. Mater. Sci. Lett. 8389

Mott W 1966 in Microindentation hardness testing (London: Butterworths) p. 9

Nilsson L 1981 Ph D thesis, University of Gothenburg, Sweden

Schroeder K, Kvist A and Ljungmark H 1972 Z. Naturforsch A27 1252

Schroeder K and Sjoblom C A 1980 High Temp. High Press. 12327

Singh B, Gupta S P and Khanna B N 1980 Pramana - J. Phys. 14509

Smakula A, Maynard M and Repucci A 1962 J. Appl. Phys. 33453

Teeter D and Frech R 1982 J. Chem. Phys. 76799 